\title{
Enamel protection made easy
}

Hydroxyapatite has been found to have remarkable remineralising effects on initial lesions of enamel, protects against dental erosion, and can be used as part of an everyday oral care regimen to form a protective layer over the enamel. ${ }^{1}$

As such, Curaprox's Black Is White toothpaste is an ideal solution for patients that suffer from tooth decay.

In addition to the toothpaste's 15,000 ppm hydroxyapatite, the Black Is White formula is SLS and triclosan free, supports salivary functions with $950 \mathrm{ppm}$ fluoride and uses the absorption qualities of activated carbon to remove discolouration safely and effectively without abrading or bleaching.

And because it can be used daily without any limitations, Curaprox's toothpaste can ensure that patients' teeth are protected at all times - not just when they visit the dentist.

The all-round nature of the formula makes it a perfect toothpaste for anyone, but if you have concerns about a patient's enamel, then why not recommend Black Is White?

For more information call 01480 862084, email info@curaprox.co.uk or visit www.curaprox.co.uk

1. Pepla E, Besharat L K, Palaia G, Tenore G, Migliau G. Nano-hydroxyapatite and its applications in preventive, restorative and regenerative dentistry: a review of literature. Ann Stomatol (Roma) 2014; 5: 108-114.

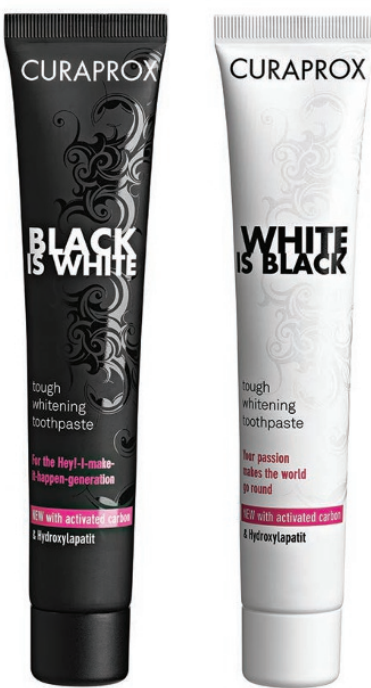

\section{Reliable and predictable bonding}

APC Flash-Free adhesive coated appliance system from 3M Oral Care eliminates the flash removal step in bonding, reduces variability and saves time for you and your patients.

Bond times are reduced by up to $40 \%$ per bracket by eliminating the flash removal and clean-up step, allowing you to move directly from placement to cure. Furthermore, the adhesive demonstrates an excellent level of tack and workability

\section{Go with the flow}

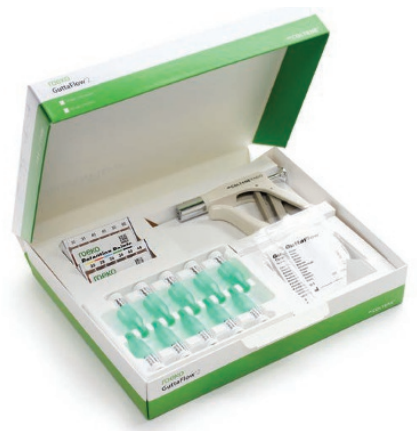

COLTENE is committed to providing dental practitioners with high quality products that allow them to improve their treatment outcomes. Nothing defines this commitment more than ROEKO GuttaFlow bioseal; here are the specifics:

- Intelligent obturation

- Upon contact with fluids the bioactive material provides the tooth with before light curing, delivering extremely reliable bond strength and particularly low failure rates of less than $2 \%$.

Find out today how APC Flash-Free adhesive coated appliance system from $3 \mathrm{M}$ Oral Care can help you. For more information, call 08458734066 or visit http://solutions.3m.co.uk/wps/portal/3M/ en_GB/orthodontics_EU/Unitek/.

$3 \mathrm{M}$ and $\mathrm{APC}$ are trademarks of the $3 \mathrm{M}$ Company.

\section{First touch-free applicator system}

Dedicated to providing dental professionals with items that improve performance within the practice, Dental Express (a trading division of Surgery Express LLP) is excited to offer the Ultramultibrush.

The world's first touch-free applicator system, the Ultramultibrush easily dispenses applicators in a simple and hygienic way. Indeed, the fully enclosed compact dispenser reduces the risk of cross contamination and, thanks to its easy-to-clean design, allows for excellent disinfection.

Furthermore, the Ultramultibrush can carry up to $50 \%$ more applicators in a single pod compared to other leading brands. This allows you to benefit from the efficiency of having more product in less space!

As part of the high quality Ultra range, the Ultramultibrush provides you with an innovative, hygienic system within your practice. To find out more, contact the expert team at Dental Express today.

Visit www.dental-express.co.uk, call 0800 7076212 or email sales@dental-express.co.uk.

- Short curing time (12-16 minutes).

With ROEKO GuttaFlow bioseal, COLTENE is providing dental professionals with an intelligent obturation material that does so much more than simply sealing and filling the root canal.

To find out more about the intelligent properties of this advanced bioseal, contact the expert team at COLTENE today. Visit www.coltene.com or call 01444235486.

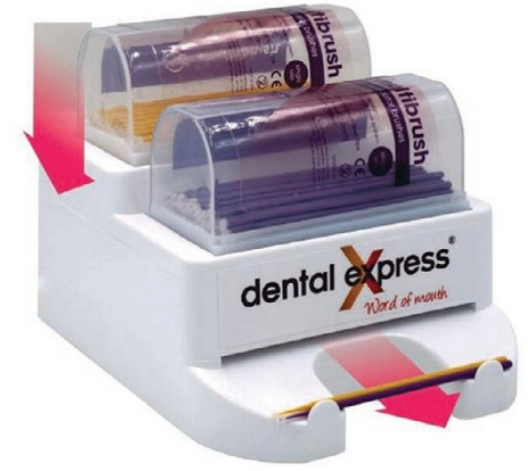

